\begin{tabular}{|l|l|l||}
\hline \multicolumn{2}{|c|}{ PublisherInfo } \\
\hline \hline PublisherName & $:$ & BioMed Central \\
\hline \hline PublisherLocation & $:$ & London \\
\hline \hline PublisherImprintName & $:$ & BioMed Central \\
\hline \hline
\end{tabular}

\title{
Dendrite guidance
}

\begin{tabular}{|l|l|l||}
\hline \multicolumn{2}{|c|}{ ArticleInfo } \\
\hline \hline ArticleID & $:$ & 3640 \\
\hline \hline ArticleDOI & $:$ & $10.1186 /$ gb-2000-1-2-reports0063 \\
\hline \hline ArticleCitationID & $:$ & reports0063 \\
\hline \hline ArticleSequenceNumber & $:$ & 37 \\
\hline \hline ArticleCategory & $:$ & Paper report \\
\hline ArticleFirstPage & $:$ & 1 \\
\hline \hline ArticleLastPage & $:$ & 4 \\
\hline \hline & & RegistrationDate : 2000-7-1 \\
ArticleHistory & $:$ & Received \\
\hline \hline ArticleCopyright & $:$ & BioMed Central Ltd2000-7-1 \\
\hline \hline ArticleGrants & $:$ & \\
\hline \hline
\end{tabular}




\begin{tabular}{|l|l|l||}
\hline ArticleContext & $:$ & 130591122 \\
\hline
\end{tabular}

\section{Joe Hao}

\section{Abstract}

The chemotropic factor semaphorin 3A has been shown to act in both the axonal and dendritic guidance of cortical pyramidal neurons.

\section{Significance and context}

The axons and dendrites of a developing neuron must grow in the proper orientation in order to make the right connections with the appropriate targets. The mechanisms by which axons and dendrites achieve proper orientation and guidance during development are not fully known, especially in the case of dendrites. Diffusible extracellular signals affect axon guidance, as well as dendritic growth and branching, suggesting that such signals may also guide dendrites. Here, Polleux et al. provide the first evidence that different compartments of the same neuron can respond in opposite ways to an identical secreted signal. Axons of pyramidal neurons are repelled by a source of semaphorin 3A (Sema3A), whereas their dendrites are attracted. This suggests a new role for Sema3A, a member of a large family of secreted and transmembrane proteins once thought to be involved only in axonal chemorepulsion. This study is also one of the first to demonstrate, in a physiological setting, the role of cyclic nucleotides in neurite guidance. The results strongly suggest that the patterning of dendrites can be regulated by extracellular chemotropic cues, and that the different response of axons and dendrites to such cues can determine neuronal morphology.

\section{Key results}

Cortical pyramidal neurons extend apical dendrites towards the marginal zone of the developing cortex, while their axons project in the opposite direction, towards the white matter. Polleux et al. show that the majority of apical dendrites from pyramidal neurons plated on a cortical slice are preferentially oriented towards the marginal zone of the slice, and that this effect is dependent on the distance between the neuron and the marginal zone. These results support the role of a signal emanating from or near the marginal zone that acts to orient and attract dendrites. Evidence that this signal is Sema3A comes from $S E M A 3 A$ null mice, in which axonal processes, normally repelled from a Sema3A source, project randomly. The authors show that $S E M A 3 A$ null mice also have random orientation of dendritic processes. These results suggest that in normal circumstances a dendrite and an axon from a given cortical neuron behave in an opposite manner to the same cue secreted near the marginal zone: dendrites 
are attracted to Sema3A while axons are repelled. Polleux et al. also show that the level of cyclic nucleotides in the neuron is critically important in the attraction of cortical dendrites by Sema3A. In particular, intracellular cyclic GMP (cGMP) levels determine how the growing dendrite interprets a Sema3A cue. The authors show that soluble guanylate cyclase (SGC), the enzyme that produces cGMP, is asymmetrically localized to the site of dendrite formation and extension. They also show that a reduction in intracellular cGMP levels by a SGC inhibitor resulted in randomly projecting cortical dendrites, with no preferential extension towards Sema3A. These data suggest that the resulting elevated cGMP levels on the dendritic side of the neuron cause the attraction to Sema3A. Inhibiting SGC did not affect the repulsion of cortical axons away from Sema3A, suggesting that cGMP signaling is specifically involved in dendrite orientation.

\section{Links}

Supplementary information to Nature 404:567-573 is available free online from Nature or the Ghosh laboratory website. A 'News and Views' feature covering the article appeared in the same issue of Nature and is available to subscribers.

\section{Conclusions}

Polleux et al. conclude that the mechanism by which neurons respond to extracellular cues in a polarized fashion through the asymmetric localization of a signaling molecule is similar to that postulated for the chemotactic responses of Dictyostelium and leukocytes. In all cases, the receptor for the signal may be uniformly distributed over the cell surface, but the specific response, whether dendritic orientation or chemotaxis, is triggered by the asymmetric localization of a signaling factor. They speculate that the differential localization of the signal transduction apparatus may be a general mechanism used by cells to generate polarized responses.

\section{Reporter's comments}

This paper provides compelling evidence for the novel role of Sema3A as an apical dendrite chemoattractant. It will now be interesting to see whether other semaphorin family members expressed in the developing cortex, and other intracellular signal molecules, are involved in dendrite orientation and guidance. Drosophila also has semaphorins, but mutants of the transmembrane semaphorin, the only one analyzed, showed no gross dendritic defects. It will be interesting to determine whether Drosophila mutants in diffusible semaphorins have defects in dendritic outgrowth or guidance. This will help determine whether the mechanisms underlying dendritic guidance are conserved from invertebrates to vertebrates, a fundamental principle that has already been demonstrated in axon guidance. 


\section{Table of links}

Nature

Supplementary information to Nature 404:567-573

Ghosh laboratory

\section{References}

1. Polleux F, Morrow T, Ghosh A: Semaphorin 3A is a chemoattractant for cortical apical dendrites.

Nature. 2000, 404: 567-573. 0028-0836 